\title{
Biomagnification of ionizable organic compounds in rainbow trout Oncorhynchus mykiss
}

Carolin Mueller ${ }^{1}$, Stefan Trapp ${ }^{2}$, Fabio Polese ${ }^{2,5}$, Sebastian Kuehr ${ }^{1,3}$ and Christian Schlechtriem ${ }^{1,3,4^{*}}$ (D)

\begin{abstract}
Background: The assessment of persistence, bioaccumulation and toxicity (PBT) is part of the regulation process of ionic organic compounds (IOCs) and a major challenge, as a commonly acknowledged approach for the estimation of the bioaccumulation potential of IOCs is still missing. The goal of the present study was, therefore, to experimentally determine the bioaccumulation of fully ionized compounds and to identify screening parameters that can indicate high bioaccumulation potential of IOCs. Three feeding studies with rainbow trout (Oncorhynchus mykiss) were carried out according to OECD TG 305. Separation of liver, gastrointestinal tract (GIT) and carcass allowed to further elucidate the tissue distribution of the individual test substances. The chemicals chosen had characteristics that made them suspect for high bioaccumulation, and included two cations (tetrabutylphosphonium bromide (TBP), trimethyloctadecyl ammonium chloride (TMOA)) and four anions (benzotriazole, tecloftalam, pentachlorophenol (PCP), MEE-phosphonate). Data on the dietary biomagnification of IOCs (strong acids) were also collected from published literature.

Results: The highest distribution factors were found for the GIT, followed by liver. However, none of the tested IOCs showed a distinct biomagnification potential, as kinetic biomagnification factors $\left(\mathrm{BMF}_{\mathrm{k}}\right)$ ranged between 0.001 and $0.05 \mathrm{~g} / \mathrm{g}$ (median $0.009 \mathrm{~g} / \mathrm{g}$ ). Cations showed lower assimilation efficiency (a) than anions, except for tecloftalam. In contrast, anions showed a considerably faster depuration rate (half-life less than 0.5 days) compared to cations (half-life of around 5 days). Sixteen potential screening parameters for BMF were calculated with a chemical property estimation tool (ACD/i-Lab) and correlated with the BMF data from this study and from literature. The number of hydrogen bond donors ( $\mathrm{nHBD}$ ) showed the highest correlation to measured BMF, but the prediction is only based on two values (one or two $\mathrm{nHBD}$ ), while the other descriptors were insignificantly correlated.

Conclusion: The suspected dietary bioaccumulation potential of the six IOCs could not be confirmed in the feeding studies with rainbow trout. The more than twenty screening parameters showed no particularly high correlation neither with the test results nor with the BMF values collected from literature. The results corroborate earlier findings that ionization lowers the tendency of a chemical for dietary bioaccumulation, compared to non-ionized chemicals. In addition to the lipophobicity of ionic molecule moieties, fast depuration seems to be a major reason for the observed low dietary bioaccumulation of ionic compounds, in particular anions. Fast depuration may happen due to rapid metabolism of charged compounds, and future studies should test this hypothesis.
\end{abstract}

Keywords: Acids, Bases, Organic electrolytes, Bioaccumulation, Risk assessment, lonic organic compounds, Fish

${ }^{*}$ Correspondence: christian.schlechtriem@ime.fraunhofer.de

${ }^{1}$ Fraunhofer Institute for Molecular Biology and Applied Ecology IME, Auf dem Aberg 1, 57392 Schmallenberg, Germany

Full list of author information is available at the end of the article

\section{Background}

The uptake of chemicals in biota and the subsequent accumulation in the food chain caused severe problems in the past [1] and is, thus, of major concern in
SpringerOpen

(c) The Author(s) 2020. This article is licensed under a Creative Commons Attribution 4.0 International License, which permits use, sharing, adaptation, distribution and reproduction in any medium or format, as long as you give appropriate credit to the original author(s) and the source, provide a link to the Creative Commons licence, and indicate if changes were made. The images or other third party material in this article are included in the article's Creative Commons licence, unless indicated otherwise in a credit line to the material. If material is not included in the article's Creative Commons licence and your intended use is not permitted by statutory regulation or exceeds the permitted use, you will need to obtain permission directly from the copyright holder. To view a copy of this licence, visit http://creativeco mmons.org/licenses/by/4.0/. 
environmental protection. Consequently, bioaccumulation is a key criterion in chemical risk assessment. Within the European Union, the regulation of Registration, Evaluation, Authorisation and Restriction of Chemicals $(\mathrm{REACH})$ requires testing of the bioaccumulation potential of substances during registration. Moreover, bioaccumulation is a criterion (together with persistence and toxicity) in the PBT assessment of substances, which are of major concern [2]. The first step of bioaccumulation assessment is usually done based on a physico-chemical screening parameter, the log octanol-water partition coefficient $\left(\log \mathrm{K}_{\mathrm{ow}}\right)$. If the threshold value of 4.5 is exceeded, studies on aquatic bioconcentration or bioaccumulation according to OECD test guidelines 305 [3] have to be conducted [2]. If the outcome of the study is a bioconcentration factor $(\mathrm{BCF})>2000 \mathrm{~L} / \mathrm{kg}$, the substance is labeled as bioaccumulative $\mathrm{B}$, and if $\mathrm{BCF}>5000 \mathrm{~L} /$ $\mathrm{kg}$ as very bioaccumulative $\mathrm{vB}$. The same criterion of $\mathrm{BCF}>5000 \mathrm{~L} / \mathrm{kg}$ is also used in other regulations (e.g., Stockholm convention [4]). Notably, a corresponding common threshold value is missing [2] for the biomagnification factor (BMF), which describes bioaccumulation through dietary exposure. Experimental determination of the bioaccumulation potential means high need for experimental animals and high costs.

The general framework for evaluating the bioaccumulation potential of substances was developed for neutral organic hydrophobic substances. However, many organic substances are partially or completely ionized under environmentally relevant conditions [5]. Due to their charge, ionic organic substances (IOCs) differ in their environmental behavior from neutral substances [6]. For ionizable and ionic compounds, the $\log \mathrm{K}_{\mathrm{ow}}$ is not considered a valid descriptor for bioaccumulation in the REACH regulation [2]. However, experimental data show that ions can also bioaccumulate in fish [7]. Additional effects, such as the ion trap and the attraction of ions through proteins, can make the accumulation of IOCs more complex. The $\log \mathrm{K}_{\mathrm{ow}}$ and also the $\mathrm{pH}$-corrected apparent partition coefficient $\left(\log \mathrm{D}_{\mathrm{ow}}\right)$ are rather weakly correlated with the BCF of ionized substances [8], questioning their value as screening parameters for the bioaccumulation potential of IOCs [7]. Studies also show that the $\mathrm{pH}$-dependent $\log \mathrm{D}_{\text {ow }}$ underestimates the sorption of ionic species by several orders of magnitude $[9,10]$. However, an alternative screening criterion to $\log \mathrm{K}_{\mathrm{ow}}$ or $\log \mathrm{D}_{\mathrm{ow}}$ is currently not established in the regulation.

An evaluation of data from REACH registrations of substances with an annual production of 1000 tons or more showed that in $18 \%$ of the cases, no bioaccumulation tests are available because the registered substance is ionically or hydrolytically unstable [11]. Whether the omission of a bioaccumulation assessment was always justified remains open. Due to the lack of suitable screening tools, IOCs have so far been omitted from QSARbased mass screening for potential PBT substances from the total number of substances registered under REACH. Due to the weak data situation, it is unclear whether IOCs can generally be absolved in terms of their bioaccumulation potential and whether the screening of the neutral species is sufficient to identify all $\mathrm{PBT} / \mathrm{vPvB}$ substances.

Several studies have described that liposomes consisting of phosphatidylcholine are a suitable artificial model for biomembranes $[10,12]$. The liposome water partition coefficient $\mathrm{K}_{\text {lipw }}$ was superior to the $\mathrm{D}_{\mathrm{ow}}$ as predictor for the sorption of ionic species to biomembranes $[9,10]$. Therefore, the $\log \mathrm{K}_{\text {lipw }}$ in connection with further distribution coefficients (e.g., the protein-water distribution coefficient) might be a feasible screening criterion for the bioaccumulation of IOCs $[7,13]$. Other parameters suggested for this purpose are the $\mathrm{pH}$-adjusted $\log \mathrm{D}_{\text {ow }}$ for partly ionized compounds [8], the polar surface area (PSA) for oral uptake [14, 15], and various structural parameters for oral bioavailability $[16,17]$.

The ionized fraction of acids and bases generally shows a lower uptake from water into fish and hence a lower BCF than the neutral molecules $[6,18-20]$. However, data from fish feeding studies examined in the work of Arnot and Quinn [21] indicate that IOCs do not necessarily show a lower uptake from dietary ingestion than neutral compounds with similar properties, and the charge may have no decisive influence on the intake in the gastrointestinal tract (GIT) [20]. Due to the lower membrane permeability of IOCs and the higher transepithelial resistance of the gills compared to the GIT, it is likely that IOCs are better received via the GIT. The associated greater permeability of the GIT and the longer residence time in the GIT support this assumption. In this study, the bioaccumulation potential of selected IOCs was evaluated in a dietary uptake study carried out according to OECD TG 305 [3], combined with organ-specific analysis. The chemicals tested included two cations (tetrabutylphosphonium bromide (TBP), trimethyloctadecyl ammonium chloride (TMOA)) and four anions ((3-(3-(2H-benzo[d] [1,2,3]triazol-2-yl)-5-(tertbutyl)-4-hydroxyphenyl)-propanoic acid (benzotriazole), 2,3,4,5-tetra-chloro-6-[[(2,3-dichloro-phenyl)-amino] carbonyl]benzoic acid (tecloftalam), pentachlorophenol (PCP) and mono-2-ethylhexyl(2-ethylhexyl)phosphonate (MEE-phosphonate). These chemicals were selected as their characteristics (e.g., high $\log \mathrm{D}_{\text {ow }}$; long lipophilic side chains) made them suspect for high biomagnification. For each of the six substances, twenty potential screening parameters for BMF were derived with estimation tools to assess their capability of predicting 
biomagnification factors. Correlations were performed for BMF data measured in the present study and BMF data collected from published literature. The ultimate goal of the study was to elucidate whether IOCs can show sufficient bioaccumulation potential to be classified as "bioaccumulative", and to identify screening parameters that can identify this potential beforehand.

\section{Methods}

\section{Literature search and identification of candidate IOCs for testing \\ Dataset definition}

Whole-body dietary BMF values in fish were collected from scientific literature (published until December 2017). Reliable dietary BMF values were selected based on quality criteria set by OECD TG 305 [3] and Arnot and Quinn [21], namely: (i) for $\mathrm{BMF}_{\mathrm{ss}}$, the assumption of steady state between uptake and depuration kinetics could be verified based on reported time-resolved concentration data or depuration rate (in the latter case, the time to reach $90 \%$ steady state had to be lower than the uptake phase duration [22]); (ii) fish growth was explicitly accounted for using a growth-corrected depuration rate $\left(k_{2 \mathrm{~g}}\right)$; and (iii) the assimilation efficiency $\alpha$ had been estimated to be $\leq 100 \%$. Lipid-normalized BMF values were not considered for the assessment, given that IOCs such as perfluorinated substances do not primarily adsorb to lipids.

\section{Selection of predictors}

Molecular descriptors were selected to assess their capability of empirically predicting dietary BMF for ionizable substances and include: (i) acid dissociation constants $\left(\mathrm{pK}_{\mathrm{a}}\right)$; (ii) molar mass, molar volume and McGowan's estimation of molar volume; (iii) partition coefficients $\mathrm{K}_{\mathrm{ow}}, \mathrm{D}_{\mathrm{ow}}$ and $\mathrm{K}_{\mathrm{HSA}}$ (human serum albumin-water); (iv) solubility at neutral $\mathrm{pH}$; (v) Lipinski's properties, namely topological polar surface area (TPSA), number of rotatable bonds (nRB), number of hydrogen bond donors (nHBD) and acceptors (nHBA) and total number of hydrogen bonds (nHBD $+\mathrm{A})$; (vi) volume of distribution. Predicted values for each descriptor were estimated using ACD/i-Labs.

\section{Selection of compounds for experimental testing}

The database of BMF values and molecular descriptors was used to identify IOCs suspect of high dietary bioaccumulation. Substance availability and feasibility of extraction and analysis were also relevant. Permanently charged cationic and lipophilic quaternary ammonium compounds were first considered as relevant candidates for selection. Similarly, permanent lipophilic anions were also to be included in the examination. Permanent ions will presumably show a different accumulation due to their poor membrane permeability and uptake into the circulation system via the paracellular pathway [23]. Ionic surfactants were also found to be of interest because, due to the interfacial activity, a completely different sorption behavior can be expected. However, polyfluorinated compounds were excluded because they were studied elsewhere, and a BMF data set from published literature is available. Based on these considerations, the two cations TBP and TMOA were chosen. Both substances have long lipophilic side chains, and Ross et al. [24] showed that lipophilic permanent cations (like triphenylphosphonium compounds) can rapidly cross membranes and accumulate in cells and mitochondria. Additionally, the four anions benzotriazole, tecloftalam, PCP and MEE-phosphonate were selected for testing, which had either high $\log \mathrm{D}_{\mathrm{ow}}$ or high partition coefficients to protein $\left(\mathrm{K}_{\mathrm{HSA}}\right)$. The test substances along with chemical structure, CAS number and physicochemical properties are presented in Table 1. Additionally, the properties necessary for Lipinski's 'rule of five' and Veber's rules were collected for the tested IOCs (see Additional file 1: S2.3, Table S6) $[16,17]$.

\section{Feeding studies \\ Standards and reagents}

TBP (chemical purity 98\%), TMOA (chemical purity 95\%) and PCP (chemical purity 97\%) were purchased from Sigma Aldrich. Benzotriazole (chemical purity 95\%) was purchased from BOC Sciences, tecloftalam (chemical purity 95.3\%) was purchased from APIChem Technology and MEE-phosphonate (chemical purity 95\%) was purchased from TCI Chemicals. Unless otherwise noted, all solvents were obtained from ChemSolute and from Sigma Aldrich and were of the quality purum or suprapur.

\section{Study design}

Juvenile rainbow trout with an average weight of $5.42 \pm 1.14 \mathrm{~g}$ were fed three test diets supplemented with two different IOCs for 14 days each at a rate of $2 \%$ of their body weight. The fish were held under flow-through conditions (flow rate of $15.6 \mathrm{~L} / \mathrm{h}$ ) at a temperature of $14 \pm 2{ }^{\circ} \mathrm{C}$ under a $16: 8 \mathrm{~h}$ light-dark cycle and constant aeration. The accumulation phase (days -14 to 0 ) was followed by a 14-day depuration phase (days 0 to 14), in which the test diet was replaced by non-spiked trout feed. On certain dates during the study, five animals were sampled from the test basin. Organ and carcass samples were dissected and prepared for IOC analysis. At the beginning of the study (day -14), five animals were sampled for IOC analysis to quantify initial background levels. The biomagnification studies were carried out following the principles of the OECD TG 305 [3] and in accordance 
Table 1 Chemical structure, CAS number and physicochemical properties of test substances

\begin{tabular}{|c|c|c|c|c|c|}
\hline Substance (CAS) & Structure & $\mathrm{K}_{\mathrm{HSA}}$ & $\log D_{\text {ow }}$ pH 7.4 & $\log D_{\text {ow }}$ pH 3.0 & $z$ \\
\hline TBP (3115-68-2) & & 3.12 & 1.6 & 1.6 & 1 \\
\hline TMOA (112-03-8) & $x_{16}^{c i}$ & 3.9 & 4.1 & 4.1 & 1 \\
\hline Benzotriazole (84268-36-0) & & 5.03 & 0.8 & 3.5 & -1 \\
\hline Tecloftalam (76280-91-6) & & 6.18 & 2.3 & 5.5 & -1 \\
\hline PCP (87-86-5) & & 5.35 & 2.4 & 5.1 & -1 \\
\hline MEE-phosphonate (14502-03-0) & & 3.77 & 0.0 & 3 & -1 \\
\hline
\end{tabular}

nd no data, $z$ charge. Source: see text.

with the German animal welfare act under a Landesamt für Natur, Umwelt und Verbraucherschutz NordrheinWestfalen, Germany permit (81-02.04.2018.A023).

Feed preparation and fish rearing are described in detail in Additional file 1: S1.1 and S1.2.

\section{Sample preparation}

All feed and fish samples were processed by solid-liquid extraction. Carcass samples were first homogenized with an IKA ULTRA-TURRAX ${ }^{\circledR}$ attached to a dispersing tool (basic, S25N-10G). Approximately $1 \mathrm{~g}$ of carcass homogenate, the whole GIT and liver samples, as well as aliquots of $1 \mathrm{~g}$ of feed were extracted and used for the analysis of IOC concentrations. To all samples, $4 \mathrm{~mL}$ methanol were added prior to homogenization. The samples were homogenized for $30 \mathrm{~s}$ with the dispersing tool attached to an ULTRA-TURRAX ${ }^{\circledR}$, treated in an ultrasonic bath for $10 \mathrm{~min}$ and then centrifuged for $5 \mathrm{~min}$ at $5000 \mathrm{rpm}$. The supernatants were transferred into a volumetric flask. This step was repeated twice and the combined supernatants were filled up to the $10 \mathrm{~mL}$ mark with methanol.

Prior to sample extraction, spike recovery of the used extraction protocol was assessed for the different sample matrices. Therefore, blank matrices (GIT, liver, carcass) were spiked with a known amount of test substance followed by extraction as described above. The respective recovery rates were calculated.

\section{IOC analysis}

Chemical analysis of the test substances was performed by liquid chromatography with coupled mass spectrometry and all analyses were performed in multiple reaction monitoring mode. For further instrumental and chromatographic details, see Additional file 1: S1.3.

Quantification was performed externally using an at least 6-point matrix-matched calibration. Here, a calibration range of $0.05-20 \mu \mathrm{g} / \mathrm{L}$ for the cations and $0.25-50 \mu \mathrm{g} / \mathrm{L}$ for the anions were used. Coefficients of correlation of the calibration function were estimated as $0.991-0.999$. Prior to chemical analysis of extracts exceeding the calibration ranges, the extracts of the different fish compartments were diluted with methanol (1:80 to $1: 1)$ depending on their IOC content. The extracts of the feed samples were diluted with methanol by a factor of 1000 yielding concentrations within the calibration range. Only values greater than three times the background [lowest calibration point (=defined LOQ)] were assessed as valid. Concentrations of test substances in fish feed and fish tissue samples were calculated based on the recorded weight of the analyzed sub-sample. 


\section{Data evaluation}

The data evaluation for specific growth rate (SGR), feed conversion ratios (FCR) and calculation of biomagnification factors (BMF) followed Annex 7 of OECD TG 305 [3] and are described in detail in Additional file 1: S1.4.

\section{Results}

\section{BMF data from literature}

A BMF dataset was compiled from the results of 6 published articles [22, 25-29]. The dataset includes 25 dietary BMF values for a total of 21 compounds, among them 11 strong acids, 7 weak acids and 2 bases. All compounds and empirical data (kinetic $\mathrm{BMF}_{\mathrm{k}}$ and steady state $\mathrm{BMF}_{\mathrm{sS}}$, $\alpha, k_{2}$ ) are shown in Additional file 1: S2.1. The highest BMF values were determined for per- and polyfluorinated compounds, with a maximum $\mathrm{BMF}_{\mathrm{k}}$ of $1.0 \mathrm{~g} / \mathrm{g}$ for perfluorotetradecanoic acid. Relatively few values, and all $<0.1 \mathrm{~g} / \mathrm{g}$, were found for bases. The overall median $\mathrm{BMF}_{\mathrm{k}}$ was calculated to be $0.178 \mathrm{~g} / \mathrm{g}$. Literature data have been checked for correlation with the chosen screening parameters (see section Additional file 1: S2.2-3).

\section{Feeding studies}

\section{Homogeneity, content and stability of IOCs in fish feed}

The homogenous distribution and the content of the IOCs in the spiked experimental diets were confirmed directly after preparation by analysis of five individually processed replicates. The relative standard deviations of the concentrations were $<10 \%$, confirming the homogenous distribution of the test substances on the spiked feed (Additional file 1: S2.4.1). The nominal test concentration of all IOCs was $30 \mathrm{mg} / \mathrm{kg}$ and for cationic substances test concentrations of $23.8 \mathrm{mg} / \mathrm{kg}$ for TBP and $25.9 \mathrm{mg} / \mathrm{kg}$ for TMOA were applied. For anionic IOCs, the dietary concentrations were 31.9, 27.5, 20.3 and $29.6 \mathrm{mg} / \mathrm{kg}$ for benzotriazole, tecloftalam, PCP and MEEphosphonate, respectively. At the end of the study, 86.2$109 \%$ of the substances were recovered and thus, the feed approved as sufficiently stable.

\section{Growth rate and feed conversion}

No mortality or abnormalities of the animals' behavior were observed during the biomagnification study. FCRs and SGRs of experimental animals during the fish feeding study are shown in Additional file 1: S2.4.2.

\section{Spike recovery experiments}

Mean recovery rates of the IOCs extracted from spiked fish compartments were in the range of $81.4 \%$ (benzotriazole in GIT) and 115\% (TMOA in carcass). For GIT, the recovery rates ranged from 81.4 to $86.7 \%$ for all ions except of tecloftalam, where a recovery of $104 \%$ was determined. Recoveries from liver ranged between 85.9 and $107 \%$ and comparable data were determined for carcass (83.8-115\%) (Additional file 1: S2.4.3).

\section{Biomagnification of IOCs in rainbow trout}

The concentrations of the IOCs in the test animals (whole fish) during the uptake and the depuration phase are presented in Additional file 1: S2.4.4, Figure S2-S4. At the end of the uptake phase, concentrations of 0.640 and $1.029 \mathrm{mg} / \mathrm{kg}$ were determined for TMOA and benzotriazole, respectively. For TMOA the highest tissue concentrations were found after $10 \mathrm{~h}$ of depuration with $1.31 \mathrm{mg} / \mathrm{kg}$. Lower concentrations were found for TBP, tecloftalam, PCP and MEE-phosphonate, with 0.0338, $0.0454,0.187$ and $0.293 \mathrm{mg} / \mathrm{kg}$, respectively.

The $\alpha$-values of the test substances ranged from 0.0155 (TBP) to 0.931 (MEE-phosphonate). An $\alpha$-value of 2.03 was calculated for benzotriazole which is supposed to be an artefact resulting from the calculation of whole fish assimilation efficiencies based on the IOC concentrations measured in the different fish matrices. Depuration rate constants $\left(k_{2}\right)$ were determined by linear regression of lntransformed tissue concentrations measured during the depuration phase (Fig. 1). Data of the individual compartments can be found in Additional file 1: Figures S5-S7.

The highest depuration rate was observed for tecloftalam and MEE-phosphonate, with $k_{2}$ values of 2.96 and 2.06 day $^{-1}$, respectively, followed by PCP (1.79 day $\left.^{-1}\right)$, benzotriazole $\left(1.24 \mathrm{day}^{-1}\right)$, TBP $\left(0.156\right.$ day $\left.^{-1}\right)$ and TMOA $\left(0.173\right.$ day $\left.^{-1}\right)$.

Considering the depuration rates and assimilation efficiencies, BMF values were calculated. Growth corrected $\mathrm{BMF}_{\mathrm{kg}}$ values ranged from 0.00129 (tecloftalam) to $0.0463 \mathrm{~g} / \mathrm{g}$ (TMOA) (Table 2).

\section{IOC concentrations in fish matrices and distribution factors}

Mean IOC concentrations in organs and tissues from fish sampled at the end of the accumulation phase are presented in Table 3. The concentrations of IOCs in the individual organs during the course of the study are shown in Additional file 1 (Figures S8-S16). Distribution factors (DFs) express the mean IOC concentrations in the different tissues in relation to the average concentrations estimated for the whole fish and are presented in Fig. 2.

The highest DFs were calculated for the GIT with, e.g., $12.9 \pm 2.90$ for TMOA, $10.9 \pm 1.77$ for tecloftalam, $10.7 \pm 4.05$ for TBP, $9.08 \pm 1.36$ for MEE-phosphonate and $7.14 \pm 0.711$ for PCP followed by the liver with $4.45 \pm 1.30$. All other GIT and liver DFs were $>1$, and all carcass DFs were $<1$. Overall, these results indicate an even distribution of benzotriazole in the different compartments compared to the other IOCs, which were primarily distributed in the GIT followed by the liver and only a minor fraction was found in the carcass. 

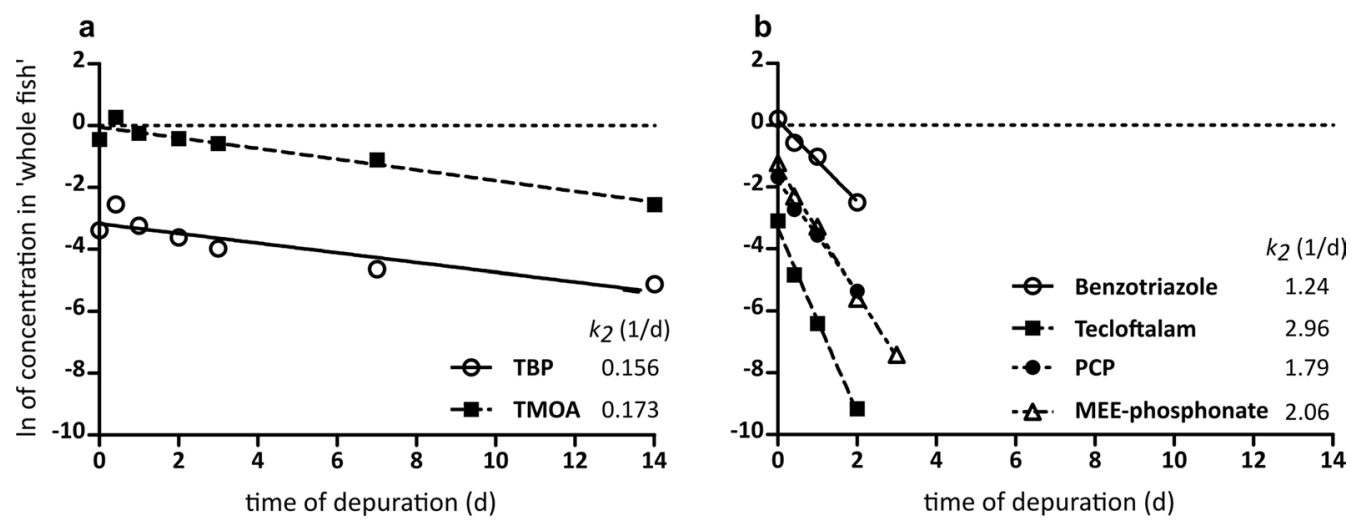

Fig. 1 IOCs in 'whole fish' during the depuration phase; a cationic and $\mathbf{b}$ anionic IOCs. Natural logarithm of calculated 'whole fish' concentrations in $\mathrm{mg} / \mathrm{kg}$ are presented (not growth corrected). Each data point is based on the results from liver, GIT and carcass data. The depuration rate constant was determined from the slope of the linear regression curve

Table $2 a, k_{2 g}\left[d^{-1}\right]$, depuration half-life calculated from $k_{2 g}\left(T_{1 / 2}\right)[d], B F_{k}$ and growth-corrected kinetic biomagnification factor $\left(\mathrm{BMF}_{\mathrm{kg}}\right.$ ) of $\mathrm{IOCs}$ in rainbow trout (whole fish) $[\mathrm{g} / \mathrm{g}]$.

\begin{tabular}{lllllll}
\hline & TBP & TMOA & Benzotriazole & Tecloftalam & PCP & MEE-phosphonate \\
\hline$a$ & 0.0155 & 0.350 & $2.03^{*}$ & 0.190 & 0.725 & 0.931 \\
$k_{2 g}$ & 0.134 & 0.151 & 1.22 & 2.94 & 1.76 & 2.04 \\
$\mathrm{~T}_{1 / 2}$ & 5.16 & 4.58 & 0.571 & 0.236 & 0.393 & 0.340 \\
$\mathrm{BMF}_{k}$ & 0.00198 & 0.0404 & 0.0328 & 0.00128 & 0.00821 & 0.00903 \\
$\mathrm{BMF}_{\mathrm{kg}}$ & 0.00231 & 0.0463 & 0.0334 & 0.00129 & 0.00822 & 0.00913 \\
\hline
\end{tabular}

* $a$-value $>1$ indicating incorrect result of calculation of whole fish assimilation efficiency.

Table 3 IOC concentrations $(\mathrm{mg} / \mathrm{kg}$ ) in fish matrices at the end of uptake phase (day 0 )

\begin{tabular}{lllllcr}
\hline Tissue & TBP & TMOA & Benzotriazole & Tecloftalam & PCP & MEE-phosphonate \\
\hline GIT & $0.362 \pm 0.122$ & $8.23 \pm 1.66$ & $0.666 \pm 0.59$ & $0.495 \pm 0.072$ & $1.34 \pm 0.119$ \\
Liver & $0.077 \pm 0.038$ & $1.02 \pm 0.190$ & $3.27 \pm 1.03$ & $0.127 \pm 0.030$ & $0.832 \pm 0.217$ \\
Carcass & $0.009 \pm 0.005$ & $0.086 \pm 0.020$ & $1.02 \pm 0.363$ & $0.008 \pm 0.004$ & $0.074 \pm 0.030$ & $0.082 \pm 0.045$ \\
Whole fish & 0.034 & 0.640 & 1.029 & 0.045 & 0.187 & 0.293 \\
\hline
\end{tabular}
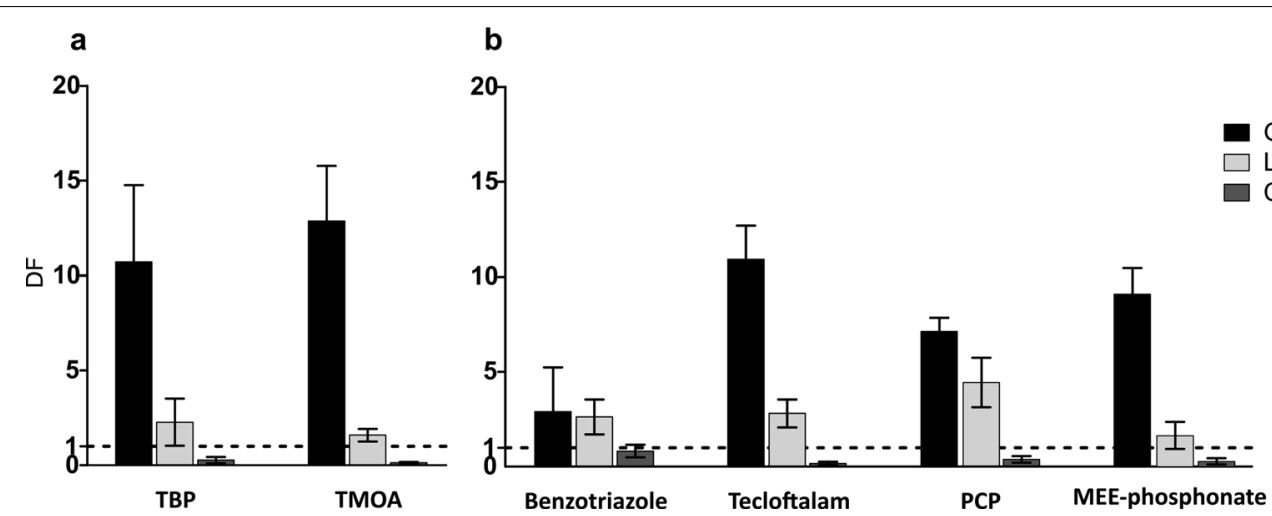

Fig. 2 Tissue distribution factors (DF) for IOCs in specific tissue at the end of uptake; a cations and $\mathbf{b}$ anions. The DF values for the different tissues are calculated in relation to the calculated 'whole fish' (DF $=1$; dotted line) 


\section{Tissue depuration kinetics}

The highest growth-corrected depuration rate constant $\left(k_{2 \mathrm{~g}}\right)$ in GIT was calculated for tecloftalam (2.25 day $\left.^{-1}\right)$, MEE-phosphonate $\left(2.00\right.$ day $\left.^{-1}\right)$ and PCP $\left(1.55\right.$ day $\left.^{-1}\right)$. In liver, high growth-corrected depuration rates were observed for PCP $\left(1.89 \mathrm{day}^{-1}\right)$ and benzotriazole $\left(1.00\right.$ day $\left.^{-1}\right)$ in contrast to TBP and TMOA for which only lower depuration rate constants of 0.224 and 0.0862 day $^{-1}$ were calculated. PCP $\left(2.06\right.$ day $\left.^{-1}\right)$, TBP $\left(1.95 \mathrm{day}^{-1}\right)$ and benzotriazole $\left(1.22 \mathrm{day}^{-1}\right)$ showed distinct depuration rate constants for carcass. However, a minor growth-corrected depuration rate constant was calculated for TMOA $\left(0.0557 \mathrm{day}^{-1}\right)$. No depuration rate constants could be calculated for tecloftalam and MEEphosphonate for liver and carcass as tissue concentrations during depuration were below LOQ (Table 4).

Estimation of additional bioaccumulation indicators The measured $\mathrm{BMF}_{\mathrm{kg}}$ values were contrasted to the $\mathrm{BCF}$ values estimated with the empirical regressions of Fu et al. [8] or the rule-based method of Meylan et al. [30] (Table 5). Notably, the highest BCF value was estimated for tecloftalam, for which the lowest BMF was measured.

\section{Discussion}

\section{Interpretation of measured BMF}

Biomagnification could not be demonstrated for any of the IOCs tested in this study. The median of the six experimental BMF was $0.0087 \mathrm{~g} / \mathrm{g}$, and the highest BMF was $0.0463 \mathrm{~g} / \mathrm{g}$ (TMOA), well below the proposed threshold values of 1 and $0.1 \mathrm{~g} / \mathrm{g}$. There are several possible explanations for the low biomagnification of the IOCs selected for this study. Two of the compounds, tecloftalam and MEE-phosphonate, were only detected in the GIT. This is a strong indication for slow or inhibited uptake into the organism. Similarly, TBP has a very low $\alpha$ and, therefore, also low BMF in liver, carcass and
Table 5 Comparison of estimated BCF-values [L/kg] with experimental $B M F\left(B M F_{k g, e x p},[g / g]\right)$ of the test substances

\begin{tabular}{lccl}
\hline Substance & $\mathbf{B C F}_{\mathbf{F u}}$ & $\mathbf{B C F}_{\text {Meylan }}$ & $\mathbf{B M F}_{\mathbf{k g} \text {, exp }}$ \\
\hline TBP & 17.9 & 3.2 & 0.0023 \\
TMOA & 70.7 & 3.2 & 0.0463 \\
Benzotriazole & 11.5 & 3.2 & 0.0333 \\
Tecloftalam & 85.6 & 56.2 & 0.0013 \\
PCP & 46.3 & 5.6 & 0.0082 \\
MEE-phosphonate & 32.7 & 5.6 & 0.0091 \\
\hline
\end{tabular}

whole fish. However, the median of $\alpha$-values of the six test compounds is at $0.54 \mathrm{~g} / \mathrm{g}$ and, thus, very similar to the median of literature data $(0.56 \mathrm{~g} / \mathrm{g}$, Additional file 1 : Table S4). It is also remarkable that for benzotriazole, an $\alpha$-value of $2.03 \mathrm{~g} / \mathrm{g}$ was derived, which is much higher than expected (typically $\leq 1$ ). The calculation of alpha is dependent on a good measure of the clearance of a chemical that has been taken up. This was not possible in the case of benzotriazole due to the few data points with detectable concentrations. The LOQ was supposed to be too high to allow an extended quantification of the substance elimination. The high alpha value should, thus, be treated with caution. A second reason for low BMF are the rather high depuration rates $\left(k_{2}\right)$ observed for tecloftalam, benzotriazole, PCP and MEE-phosphonate, i.e., the four acidic compounds. Overall, it can be concluded that the experimental BMF values are low due to slow uptake and rapid depuration.

\section{Comparison with literature findings}

In comparison to earlier values, the measured BMFs are low. The median of the literature BMFs is $0.178 \mathrm{~g} / \mathrm{g}$, which is 20 times higher than the median $\mathrm{BMF}_{\mathrm{kg}}$ of the six test substances. The highest BMF values in the

Table 4 Growth-corrected depuration rate constant $\left(k_{2 g}\right)\left[d^{-1}\right]$, and depuration half-life $\left(T_{1 / 2}\right)$ [d] of IOCs in rainbow trout compartments if available

\begin{tabular}{|c|c|c|c|c|c|c|}
\hline & GIT & Liver & Carcass & GIT & Liver & Carcass \\
\hline & TBP & & & TMOA & & \\
\hline$k_{2 g}$ & 0.125 & 0.202 & 1.925 & 0.200 & 0.0643 & 0.0338 \\
\hline \multirow[t]{2}{*}{$\mathrm{T}_{1 / 2}$} & 5.53 & 3.43 & 0.360 & 3.46 & 10.8 & 20.5 \\
\hline & Benzotriazole & & & Tecloftalam & & \\
\hline$k_{2 g}$ & - & 0.986 & 1.20 & 2.23 & - & - \\
\hline \multirow[t]{2}{*}{$\mathrm{T}_{1 / 2}$} & - & 0.703 & 0.578 & 0.310 & - & - \\
\hline & PCP & & & MEE-phosphonate & & \\
\hline$k_{2 g}$ & 1.53 & 1.87 & 2.04 & 1.98 & - & - \\
\hline $\mathrm{T}_{1 / 2}$ & 0.453 & 0.371 & 0.340 & 0.350 & - & - \\
\hline
\end{tabular}


literature were found for perfluorotetradecanoic acid and PFOS with kinetic BMF values of 1.00 and $0.42 \mathrm{~g} / \mathrm{g}$, respectively. The median of the experimental depuration rates is $1.5 \mathrm{~d}^{-1}$, while the median $k_{2}$ of the literature data (strong acids and PCP) is $0.07 \mathrm{~d}^{-1}$. PCP is the only test compound for which experimental data are available from earlier studies [10, 21, 31]. There, a BMF of $0.22 \mathrm{~g} / \mathrm{g}$ was found, while the BMF obtained from this study is $0.008 \mathrm{~g} / \mathrm{g}$. The main reason for the different result is the higher depuration rate $k_{2}$ (1.76 versus $0.25 \mathrm{~d}^{-1}$ in the earlier study).

\section{Screening parameters for the BMF of IOCs}

For the BMF data set collected from literature, the correlation analysis between BMF and screening parameters showed a significant correlation for the number of hydrogen bond donors (nHBD), but since the value of nHBD was either 1 or 2 , this result is of limited validity (Additional file 1: Figure S1a). The next best correlations were obtained to the partition coefficient to proteins $\log \mathrm{K}_{\mathrm{HS}}$ A $>\log \mathrm{D}_{\mathrm{ow}}>\mathrm{TPSA}>\log \mathrm{K}_{\mathrm{ow}}$, but none of these were significant. Comparing the screening parameters with BMF values of test substances obtained in this study, none of the correlations between the above mentioned screening parameters (e.g., MW, nHBD, nHBA, TPSA, RB, $\log \mathrm{D}_{\text {ow }}$ at different $\mathrm{pH}$ ) and the measured BMF are significant (not shown).

Also for the literature BMF data set, no significant correlation was shown between BMF and any of the screening parameters (Additional file 1: Table S5). Furthermore, all three distribution parameters $\left(\mathrm{K}_{\mathrm{HSA}}\right.$, calculated $\mathrm{BCF}_{\mathrm{Fu}}$ and calculated $\mathrm{BCF}_{\text {Meylan }}$ ) show a negative but insignificant correlation to the BMF values measured in this study (Additional file 1: Figure S1b). The degree of freedom of the correlation is very low, due to the low number of events $(n=6)$, explaining the low significance, but a negative trend was nonetheless not expected.

\section{Rules for oral uptake of medical drugs}

Lipinski et al. [16] presented the 'rule of 5', which predicts that poor absorption or permeation of orally applied drugs is more likely when the compound has more than 5 HBDs, 10 HBAs, the molecular weight is greater than $500 \mathrm{~g} / \mathrm{mol}$ and the $\log \mathrm{K}_{\mathrm{ow}}$ (or $\log \mathrm{D}_{\text {ow }}$ ) is greater than 5 . Of the six test chemicals, none has more than five HBDs or $>10$ HBA nor molar mass $>500 \mathrm{~g} / \mathrm{mol}$ nor $\log \mathrm{D}_{\text {ow }}>5$ at neutral pH. Tecloftalam and PCP have, however, $\log \mathrm{D}_{\mathrm{ow}}>5$ at $\mathrm{pH} 3$ (which may occur in the GIT). Veber et al. [17] did not fully corroborate the findings of Lipinksi et al. [16]. Instead they found, using a data set of 1100 oral studies with rats, that compounds which meet only the two criteria of (i) 10 or fewer rotatable bonds (RB) and (ii) polar surface area $\leq 140 \AA^{2}$ or 12 or fewer
HBDs and HBAs, will have a high probability of good oral bioavailability (in the rat). Applied to the experimental data here, all compounds have a TPSA $<140 \AA^{2}$, but TBP (17 RBs), TMOA (12 RBs) and MEE-phosphonate (12 RBs) have more than 10 RBs and would accordingly show limited oral bioavailability. Veber et al. [17] studied also data sets for the artificial membrane permeation rate. Reduced polar surface area correlated better with increased permeation rate than did lipophilicity, and increased RB number had a negative effect on the permeation rate. Taking the criteria of Lipinski and Veber together, all compounds tested in this study, apart from benzotriazole, violate at least one of the criteria for good oral uptake $[16,17]$. Summarizing, Lipinski's 'rule of 5' did not indicate low oral uptake, but Veber's rules indicated low oral bioavailability of TBP, TMOA and MEEphosphonate but not for the other three compounds. However, limited uptake from the GIT was only observed for three of the compounds, namely TBP, TMOA and tecloftalam, which is likely to be the main reason for the low observed BMF.

\section{Evaluation of screening parameters}

None of the screening parameters or BCF estimation methods was of real value when applied to the experimental results of the six test substances. This can be partly explained by the low permeability and low bioavailability of the test substances in the gut, but was obviously mostly caused by rapid elimination from the fish, possibly induced by rapid metabolism, e.g., conjugation. All ionic compounds have at least one reactive group - the charged moiety-and living organisms may form conjugates with such compounds [32]. Most of the screening parameters target partitioning (K-values, log D) or adsorption efficiency (Lipinski parameters), but not metabolism. Interestingly, perfluoroalkyl substances (PFAS), a compound class where biotransformation is absent [33], had the highest literature BMF values, and eight of the ten highest BMF values from literature are for per- or polyfluorinated compounds (Additional file 1: Table S4). It may be concluded that a single screening parameter, that targets partitioning or uptake but is not related to metabolism, cannot satisfyingly predict BMF of IOCs.

\section{Earlier screening studies for bioaccumulation of IOCs}

For neutral compounds, BCF and BMF are related via the depuration rate $\left(k_{2}\right)$ but such a clear relation lacks for ionic compounds [34]. Benchmarking of BMF versus BCF may provide useful evidence for the bioaccumulation assessment [2]. Nendza et al. [19] screened data sources for aquatic bioaccumulation and collected experimental and physicochemical data of 998 (training set) plus 181 
(validation set) compounds. In the training set were six bases and seven acids that were classified as "B" (bioconcentration factor $>2000 \mathrm{~L} / \mathrm{kg}$ ). However, only two of the acids in the training set, PFOS and perfluorohexane sulfonic acid, both polyfluorinated compounds, were more than $10 \%$ ionized at neutral $\mathrm{pH}$. None of the bases in the training set with $\mathrm{B}$ property showed significant ionization at test conditions (neutral $\mathrm{pH}$ ). In the validation set, two acids showed B property, namely potassium heptadecafluorooctane-1-sulfonate (also a fluoro-compound) and PCP, plus two amphoteric compounds. The ionization status of the latter is unknown but their $\log \mathrm{D}_{\mathrm{ow}}$ values indicate little ionization. PCP has a $\mathrm{pK}_{\mathrm{a}}$ of 4.6, i.e., it depends on the test $\mathrm{pH}$ whether it is ionized or not (at usual test $\mathrm{pH}$ of 7.5 it is), and the sulfonate is a strong acid. Summarized, all acids and bases that are labeled B in this large dataset are either mostly non-ionized or are polyfluorinated sulfonic acids, with the exception of PCP which was listed in this data set with an experimental BCF value of $4898 \mathrm{~L} / \mathrm{kg}$. All compounds in the data set of Nendza et al. [19] that showed high bioaccumulation were "not readily biodegradable", and there was a strong relation between BCF and degradation half time. All acids and bases that showed a high BCF had also a high $\log \mathrm{D}_{\mathrm{ow}}>3$, but as mentioned, this were non-ionized electrolytes, except the polyfluorinated compounds.

In the BCF fish database of $\mathrm{Fu}$ et al. [8], an experimental BCF value for PCP of only $10 \mathrm{~L} / \mathrm{kg}$ was listed, which is in contradiction to the high $\mathrm{BCF}$ value described by Nendza et al. [19] but confirming the low BMF observed in this study. None of the anions or cations listed by $\mathrm{Fu}$ et al. [8] showed any bioaccumulation above the criterion for B (>2000). The highest BCF among the acids $(n=74)$ was for tefluthrin, cyhalothrin (both not ionized at test $\mathrm{pH}$ ) and 2,4,5-trichlorophenol (BCF $1800 \mathrm{~L} / \mathrm{kg}, \mathrm{pK}_{\mathrm{a}}$ at 7.10 and thus about half neutral, half ionized at test conditions). Mostly ionized acids, like 2,3,4,6-tetrachlorophenol ( $\mathrm{pK}_{\mathrm{a}}$ 5.64) or the mentioned PCP had BCF values clearly $<2000 \mathrm{~L} / \mathrm{kg}$. Similarly, out of the 65 data sets for bases, only one named azocyclotin had a BCF $>2000$, but that compound has a $\mathrm{pK}_{\mathrm{a}}$ of 2.74 and is, thus, completely non-ionized at neutral $\mathrm{pH}$. Among the mostly ionized bases $\left(\mathrm{pK}_{\mathrm{a}}>9\right)$, fenpropidin showed the highest experimental BCF with $160 \mathrm{~L} / \mathrm{kg}$.

Fu et al. [8] made correlations between BCF and log $\mathrm{D}_{\text {ow }}$. Interestingly, acids with high $\mathrm{pK}_{\mathrm{a}}$ (mostly neutral) showed an excellent correlation between the two parameters $\left(R^{2}\right.$ was 0.91$)$, and the regression had high slope and low y-axis intercept. Also for mostly neutral bases, the correlation of $\log \mathrm{D}_{\text {ow }}$ to BCF was high $\left(R^{2}\right.$ was 0.80$)$, and like before the slope of the regression line had a high slope and a low y-axis intercept. For the mostly ionized acids as well as for the mostly ionized bases, the correlation of $\log \mathrm{D}_{\text {ow }}$ to BCF was weak $\left(R^{2}\right.$ of 0.34 and 0.38 ), the slopes of the regression lines were low and the $y$-axis intercepts high. This clearly shows that $\log \mathrm{D}_{\mathrm{ow}}$ (or $\log \mathrm{K}_{\mathrm{ow}}$ ) is a good predictor for the bioaccumulation of the neutral molecule fraction of ionizable substances, but a weak predictor (if at all) for the ionized fraction. It also shows that if a compound is partly ionized only, the neutral fraction will dominate the BCF. This was confirmed by the studies of Rendal et al. [6, 18], where acids and bases in neutral form showed both higher toxicity and higher uptake into organisms.

Consequently, Armitage et al. [20] recommend to consider only the neutral fraction for bioaccumulation, if ionization is $<90 \%$. These authors also expect that biotransformation plays a crucial role for compounds with high adsorption. Arnot and Quinn [21] showed for a data set with mostly neutral compounds and evaluated by a dynamic model that BMF values follow an optimum curve, with maximum values of above $10 \mathrm{~g} / \mathrm{g}$ in the range of $\log \mathrm{K}_{\mathrm{ow}} 5-8$, but declining BMF values due to growth dilution for very highly adsorbing compounds with log $\mathrm{K}_{\mathrm{ow}}>8$. It is likely that such a BMF optimum also could be found for ionic compounds, but since the permeability of ions across membranes [23] is generally slower, the optimum BMF would be lower than that for neutral compounds.

Kierkegaard et al. [35] determined the tissue distribution of twelve cationic surfactants in rainbow trout (Oncorhynchus mykiss) following exposure via water. Rainbow trout were exposed for seven days to ten alkyl amines with chain length from 9 to $16 \mathrm{C}$ and to two quaternary alkylammonium surfactants with 10 and 14 C-chains. Different fish tissues were analyzed for surfactant residues, and the contribution to the body burden was calculated. The permanently charged quaternary ammonium compounds accumulated mostly in the gills, which indicates slow uptake and corroborates our findings. The BCF of alkyl amines increased with chain length and showed particular high accumulation in the liver. Apparent BCF values ranged from 0.1 to $1260 \mathrm{~L} / \mathrm{kg}$, hence came close but remained below the threshold of the B criterion of $2000 \mathrm{~L} / \mathrm{kg}$. The authors concluded that further studies with longer exposure time and smaller fish should be conducted on the bioaccumulative properties of cationic surfactants [35]. The $16 \mathrm{C}$ alkyl amine that showed the highest bioaccumulation potential in that study is structurally similar to TMOA, which had the highest BMF of the six test substances.

\section{Conclusions}

The bioaccumulation of six ionized organic compounds IOCs was tested in an OECD TG 305 dietary uptake study. None of the tested IOCs showed distinct 
biomagnification $\left(\mathrm{BMF}_{\mathrm{kg}}<0.1 \mathrm{~g} / \mathrm{g}\right)$ and the highest content of most IOCs was found in GIT. The low concentrations in the other tissues might be explained by the absent or limited transport into other tissues, and/or by rapid biotransformation. The only exception to that was benzotriazole, for which a rapid elimination from GIT and transfer into liver and carcass were observed. Hence, the hypothesis that IOCs show a higher bioaccumulation potential by uptake through the gastrointestinal tract (GIT) could not be confirmed. Overall, all four anionic substances showed considerably higher depuration rate than cationic ones.

The more than twenty screening parameters showed no particular high correlation neither to the test results nor to the BMF values collected from literature. The results of this study point towards uptake and elimination kinetics as being decisive for the dietary BMF of the investigated IOCs. The tissue analysis indicated that the low BMF of the investigated organic cations was due to slow uptake from GIT into blood. This was also seen for some of the organic anions, but for those, the main reason for low BMF was rapid elimination, i.e., a high depuration rate. Hence, screening parameters primarily predicting adsorption, like $\log \mathrm{K}_{\mathrm{ow}}, \log \mathrm{D}_{\mathrm{ow}}$, or the $\log \mathrm{K}_{\mathrm{HSA}}$, may not be well suited to indicate high biomagnification following dietary uptake.

The results of our study are not in contradiction to earlier findings that ionization usually lowers the tendency of a chemical to bioaccumulate, compared to non-ionized chemicals $[7,18]$. In addition to the increase in polarity caused by ionization, fast depuration seems to be a major reason for the observed low biomagnification of ionic compounds, in particular for the anions studied. Fast depuration may happen due to rapid metabolism of charged compounds, and future studies should test this hypothesis.

\section{Supplementary Information}

The online version contains supplementary material available at https://doi. org/10.1186/s12302-020-00443-1.

Additional file 1. Supplementary information.

\footnotetext{
Abbreviations

a: Assimilation efficiency; BCF: Bioconcentration factor; BMF: Biomagnification factor ( $k=$ kinetic, $k_{g}=$ growth-corrected kinetic, ss = steady state); DF: Distribution factor; IOC: Ionizable organic compound; GIT: Gastrointestinal tract; MEE-phosphonate: Mono-2-ethylhexyl(2-Ethylhexyl)phosphonate; OECD: Organization for Economic Co-Operation and Development; PBT: Persistence, bioaccumulation and toxicity; PCP: Pentachlorophenol; REACH: Registration, Evaluation, Authorization and Restriction of Chemicals; TBP: Tetrabutylphosphonium bromide; TMOA: Trimethyloctadecyl-ammonium chloride.
}

\section{Author contributions}

FP and ST carried out the literature research, FP the regression analysis and the evaluation of screening parameters. SK carried out the feeding experiments. CM supplied the sample preparations, LC-MS measurements and the methods part. CS, SK and CM participated in the study design, and its coordination. CM, ST, SK, and CS wrote and coordinated the preparation of the manuscript, FP was polishing it. All authors read and approved the final manuscript.

\section{Funding}

Open Access funding enabled and organized by Projekt DEAL. Funded by the German Federal Ministry for the Environment, Nature Conservation and Nuclear Safety within the Project FKZ 3717674070 and the Fraunhofer Institute for Molecular Biology and Applied Ecology IME.

\section{Availability of data and materials}

The datasets supporting the conclusions of this article are included within the article.

\section{Ethics approval and consent to participate}

Not applicable.

\section{Consent for publication \\ Not applicable.}

\section{Competing interests}

The authors declare that they have no competing interests.

\section{Author details}

${ }^{1}$ Fraunhofer Institute for Molecular Biology and Applied Ecology IME, Auf dem Aberg 1, 57392 Schmallenberg, Germany. ${ }^{2}$ Department of Environmental Engineering, Technical University of Denmark, Kgs Lyngby, Denmark. ${ }^{3}$ Department Chemistry and Biology, "Ecotoxicology"Work Group, University of Siegen, Siegen, Germany. ${ }^{4}$ Institute for Environmental Research, RWTH Aachen, Aachen, Germany. ${ }^{5}$ DHI A/S, Hørsholm, Denmark.

Received: 13 September 2020 Accepted: 30 November 2020

Published online: 19 December 2020

\section{References}

1. Carsen R (1962) Silent Spring, New Editio. Houghton Mifflin, Boston

2. ECHA (2017) Guidance on Information Requirements and Chemical Safety Assessment. Chapter R.11: PBT/vPvB Assessment

3. OECD (2012) "Test No 305: Bioaccumulation in Fish : Aqueous and Dietary Exposure," OECD Publishing

4. UNEP (2009) Stockholm convention on persistent organic pollutants (POPs) - Text and Annexes. Secretariat of the Stockholm Convention, Geneva

5. Franco A, Ferranti A, Davidsen C, Trapp S (2010) An unexpected challenge: ionizable compounds in the REACH chemical space. Int I Life Cycle Assess 15(4):321-325. https://doi.org/10.1007/s11367-010-0165-6

6. Rendal C, Kusk KO, Trapp S (2011) The effect of pH on the uptake and toxicity of the bivalent weak base chloroquine tested on Salix viminalis and Daphnia magna. Environ Toxicol Chem 30(2):354-359. https://doi. org/10.1002/etc.391

7. Armitage JM, Arnot JA, Wania F, Mackay D (2013) Development and evaluation of a mechanistic bioconcentration model for ionogenic organic chemicals in fish. Environ Toxicol Chem 32(1):115-128. https:// doi.org/10.1002/etc.2020

8. Fu W, Franco A, Trapp S (2009) Methods for estimating the bioconcentration factor of ionizable organic chemicals. Environ Toxicol Chem 28(7):1372-1379. https://doi.org/10.1897/08-233.1

9. Smejtek P, Wang S (1993) Distribution of hydrophobic ionizable xenobiotics between water and lipid membranes: Pentachlorophenol and pentachlorophenate. A comparison with octanol-water partition. Arch Environ Contam Toxicol 25(3):394-404. https://doi.org/10.1007/BF00210732 
10. Escher BI, Schwarzenbach RP (1996) Partitioning of substituted phenols in liposome - water, biomembrane - water, and octanol - water systems. Environ Sci Technol 30(1):260-270. https://doi.org/10.1021/es9503084

11. UBA (2018) REACH compliance: Data availiability in REACH registrations Part 2: Evaluation of data waiving and adaptations for chemicals $>1000$ tpa. Final report

12. Yamamoto H, Liljestrand HM (2004) Partitioning of selected estrogenic compounds between synthetic membrane vesicles and water: effects of lipid components. Environ Sci Technol 38(4):1139-1147. https://doi. org/10.1021/es034311w

13. Endo S, Escher Bl, Goss KU (2011) Capacities of membrane lipids to accumulate neutral organic chemicals. Environ Sci Technol 45(14):5912-5921. https://doi.org/10.1021/es200855w

14. Palm K, Luthman K, Ungell AL, Strandlund G, Artursson P (1996) Correlation of drug absorption with molecular surface properties. J Pharm Sci 85(1):32-39. https://doi.org/10.1021/js950285r

15. Ertl P (2007) Polar surface area. Wiley, Weinheim, pp 111-126

16. Lipinski CA, Lombardo F, Dominy BW, Feeney PJ (2001) Experimental and computational approaches to estimate solubility and permeability in drug discovery and development settings. Adv Drug Deliv Rev 46(1-3):3-26. https://doi.org/10.1016/S0169-409X(00)00129-0

17. Veber DF, Johnson SR, Cheng HY, Smith BR, Ward KW, Kopple KD (2002) Molecular properties that influence the oral bioavailability of drug candidates. J Med Chem 45(12):2615-2623. https://doi.org/10.1021/jm020 $017 n$

18. Rendal C, Kusk KO, Trapp S (2011) Optimal choice of pH for toxicity and bioaccumulation studies of ionizing organic chemicals. Environ Toxicol Chem 30(11):2395-2406. https://doi.org/10.1002/etc.641

19. Nendza M, Kühne R, Lombardo A, Strempel S, Schüürmann G (2018) PBT assessment under REACH: Screening for low aquatic bioaccumulation with QSAR classifications based on physicochemical properties to replace BCF in vivo testing on fish. Sci Total Environ 616-617:97-106. https://doi. org/10.1016/j.scitotenv.2017.10.317

20. Armitage JM et al (2017) Assessing the bioaccumulation potential of ionizable organic compounds: Current knowledge and research priorities. Environ Toxicol Chem 36(4):882-897. https://doi.org/10.1002/etc.3680

21. Arnot JA, Quinn CL (2015) Development and evaluation of a database of dietary bioaccumulation test data for organic chemicals in fish. Environ Sci Technol 49(8):4783-4796. https://doi.org/10.1021/es506251q

22. Martin JW, Mabury SA, Solomon KR, Muir DCG (2003) Bioconcentration and tissue distribution of perfluorinated acids in rainbow trout (Oncorhynchus mykiss). Environ Toxicol Chem 22(1):196. https://doi. org/10.1897/1551-5028(2003)022\%3c0196:batdop\%3e2.0.co;2

23. Bittermann K, Goss KU (2017) Predicting apparent passive permeability of Caco-2 and MDCK cell-monolayers: a mechanistic model. PLoS ONE 12(12):1-20. https://doi.org/10.1371/journal.pone.0190319

24. Ross MF et al (2008) Rapid and extensive uptake and activation of hydrophobic triphenylphosphonium cations within cells. Biochem J 411(3):633-645. https://doi.org/10.1042/BJ20080063

25. Fisk AT, Norstrom RJ, Cymbalisty CD, Muir DGG (1998) Dietary accumulation and depuration of hydrophobic organochlorines: Bioaccumulation parameters and their relationship with the octanol/water partition coefficient. Environ Toxicol Chem 17(5):951-961. https://doi.org/10.1897/15515028(1998)017\%3c0951

26. Nyholm JR, Norman A, Norrgren L, Haglund P, Andersson PL (2009) Uptake and biotransformation of structurally diverse brominated flame retardants in zebrafish (Danio rerio) after dietary exposure. Environ Toxicol Chem 28(5):1035-1042. https://doi.org/10.1897/08-302.1

27. Inoue $Y$ et al (2012) Comparison of bioconcentration and biomagnification factors for poorly water-soluble chemicals using common carp (Cyprinus carpio L.). Arch Environ Contam Toxicol 63(2):241-248. https:// doi.org/10.1007/s00244-012-9761-8

28. Lee H, De Silva AO, Mabury SA (2012) Dietary bioaccumulation of perfluorophosphonates and perfluorophosphinates in juvenile rainbow trout: Evidence of metabolism of perfluorophosphinates. Environ Sci Technol 46(6):3489-3497. https://doi.org/10.1021/es204533m

29. Goeritz I, Falk S, Stahl T, Schäfers C, Schlechtriem C (2013) Biomagnification and tissue distribution of perfluoroalkyl substances (PFASs) in market-size rainbow trout (Oncorhynchus mykiss). Environ Toxicol Chem 32(9):2078-2088. https://doi.org/10.1002/etc.2279

30. Meylan WM, Howard PH, Boethling RS, Aronson D, Printup H, Gouchie S (1999) Improved method for estimating bioconcentration/bioaccumulation factor from octanol/water partition coefficient. Environ Toxicol Chem 18(4):664-672. https://doi.org/10.1002/etc.5620180412

31. Xiao R, Adolfsson-Erici M, Åkerman G, Mclachlan MS, Macleod M (2013) A benchmarking method to measure dietary absorption efficiency of chemicals by fish. Environ Toxicol Chem 32(12):2695-2700. https://doi. org/10.1002/etc.2361

32. Polesel F, Andersen HR, Trapp S, Plósz BG (2016) Removal of antibiotics in biological wastewater treatment systems - a critical assessment using the activated sludge modeling framework for xenobiotics (ASM-X). Environ Sci Technol 50(19):10316-10334. https://doi.org/10.1021/acs. est.6b01899

33. Martin JW, Mabury SA, Solomon KR, Muir DCG (2003) Dietary accumulation of perfluorinated acids in juvenile rainbow trout (Oncorhynchus mykiss ). Environ Toxicol Chem 22(1):189-195. https://doi.org/10.1002/ etc.5620220125

34. Goss KU, Linden L, Ulrich N, Schlechtriem C (2018) Revisiting elimination half live as an indicator for bioaccumulation in fish and terrestrial mammals. Chemosphere 210:341-346. https://doi.org/10.1016/j.chemospher e.2018.07.017

35. Kierkegaard A, Chen C, Armitage JM, Arnot JA, Droge S, McLachlan MS (2020) Tissue distribution of several series of cationic surfactants in rainbow trout (Oncorhynchus mykiss) following exposure via water. Environ Sci Technol 54(7):4190-4199. https://doi.org/10.1021/acs.est.9b07600

\section{Publisher's Note}

Springer Nature remains neutral with regard to jurisdictional claims in published maps and institutional affiliations.

\section{Submit your manuscript to a SpringerOpen ${ }^{\odot}$ journal and benefit from:}

- Convenient online submission

- Rigorous peer review

- Open access: articles freely available online

- High visibility within the field

- Retaining the copyright to your article

Submit your next manuscript at springeropen.com 